\title{
DOS ARBUSTOS NOTABLES DEL ESTADO DE YUCATAN.
}

\author{
Por FAUSTINO MIRANDA
}

del Instituto de Biologia, U.N.A. M.

\section{Malpighia souzae sp. nov. (fig. 1)}

Frutex 2-3 m. altus, ramulis albo vel griseo-tomentuloso-sericeis. Folia membranacea vel chartacea, petiolis ad $2 \mathrm{~mm}$. longis, pubescentibus; lamina late elliptica vel ovata, 3-5.7 cm. longa, 1.5-3.2 cm. lata, acuta vel abrupte breviterque acuminata, basi late cuneata vel rotundata, integerrima, glabrata, costa supra paulum, subtus valde prominente, nervis lateralibus utroque latere ad 6, inconspicuis. Cymae breves, panciflorae, axillares vel subterminales, breviter peduculatae vel sessiles, albo vel fulvotomentulosae, pedicellis gracilibus 9-10 $\mathrm{mm}$. longis. Sepala lanceolata, 2.5-3 mm. longa, tomentulosa, 6-glandularia. Petala rosea, inaequatia, longe unguiculata, laminis late ellipticis vel obovatis, $6 \mathrm{~mm}$. longa, 3.5-4 mm. lata. Stamina 10, alterne inaequalia, duobus petalis postico-lateralibus oppositis robustioribus. Drupa valde carnosa, subgloboso-trigona vel. trilobata, longitudinaliter trisulcata, 1.2-2.5 cm. longa, 1.7-3 cm. lata.

Arbusto de 2 a $3 \mathrm{~m}$. de alto. Ramas y ramillas gráciles, opuestamente ramificadas, de corteza gris, entrenudos de 1-3 cm. de largo, con las ramillas jóvenes y las yemas blanco o gris tomentuloso seríceas con pelos malpigiáceos. Hojas dísticas o subdísticas, membranosas o cartáceas, pecíolos de unos $2 \mathrm{~mm}$. de largo, pubescentes, tomentulosos cuando jóvenes, canaliculados arriba; lámina aovada o anchamente elíptica, 3-5.7 x 1.5-3.2 cm., aguda a abruptamente corto acuminada (la punta frecuentemente obtusa), anchamente cuneada a redondeada en la base, entera, de costilla poco saliente en el haz, prominente en el envés, nervios laterales unos 6 de cada lado, poco conspicuos, cuando joven con pelos malpigiáceos sobre

Miranda F. 1957. Dos arbustos notables del estado de Yucatán. Boletín de la Sociedad Botánica de México 21: 8-14. 
el nervio medio hacia la base y pocos pelos esparcidos en el envés, después glabra, con una pequeña glándula cerca del borde a cada lado hacia la base. Cimas cortas paucifloras, axilares o con frecuencia subterminales, cortamente (hasta $6 \mathrm{~mm}$.) pedunculadas o sentadas, blanco o fulvo tomentosas, con brácteas de 1-1.5 mm. de largo, aovadas, tomentulosas; pedicelos gráciles de 9-10 $\mathrm{mm}$. de largo, tomentulosos, bracteolados y articulados poco abajo de la mitad, bracteolas muy pequeñas; flores rosadas,

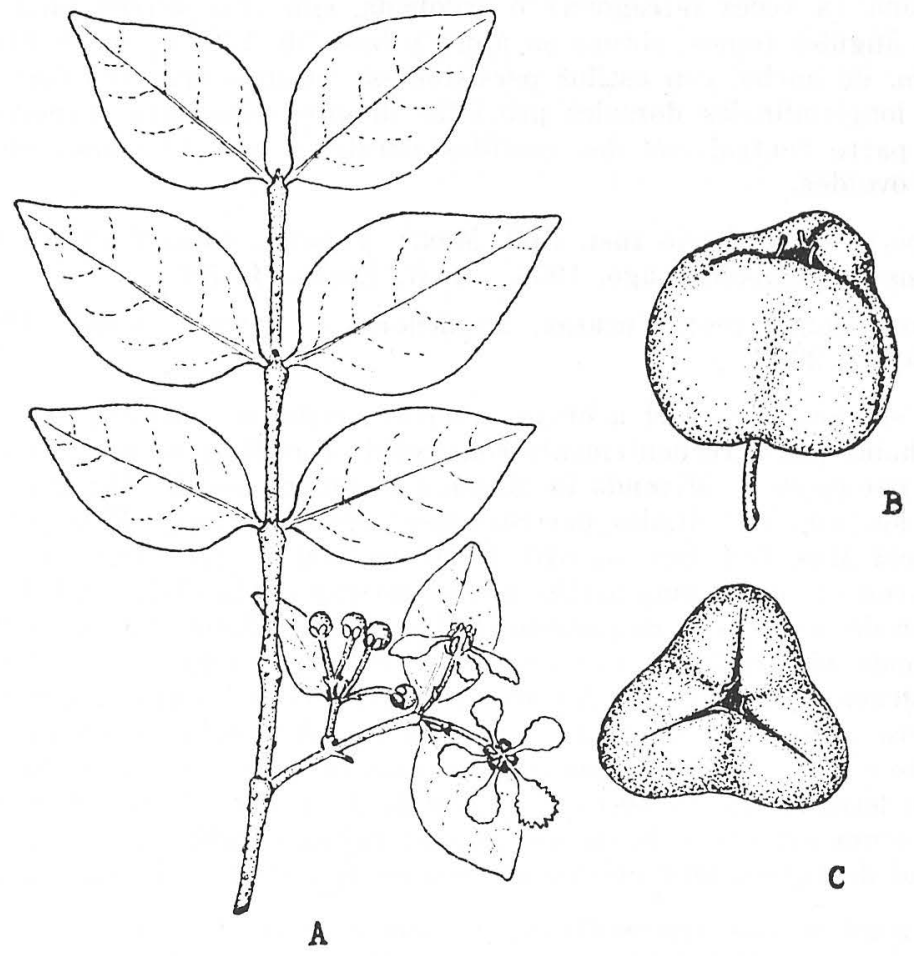

Fig. 1.-Malpighia souzae. A, rama con hojas y flores; B, fruto visto lateralmente; $\mathrm{C}$, fruto visto desde arriba.

de 1.5-1.6 $\mathrm{cm}$. de anchas; sépalos lanceolados, de $3 \mathrm{~mm}$. de largo, fulvo tomentulosos y con 6 glándulas (dos sépalos con 2 glándulas, dos con 1 y uno eglandular) elípticas, glabras, casi de la mitad de la longitud de los sépalos; pétalos más o menos desiguales, de unos $6 \mathrm{~mm}$. de largo por 3.5-4 mm. de ancho, unguiculados, uno con uña más larga y lámina laciniado 
fimbriada, de láminas anchamente elípticas a obovadas, pubescentes en el dorso hacia la línea media; estambres 10, alternadamente desiguales, los dos opuestos a los pétalos póstero laterales (por consiguiente, entre un sépalo de dos glándulas y otro de una) con los filamentos y anteras más robustos, y en consecuencia algo más largos que todos los demás, aunque con filamentos más cortos que los opuestos a los sépalos, todos ellos glabros, soldados hacia la base; ovario y estilos glabros, uno de los estilos una cuarta parte más corto que los otros dos, los tres algo dilatados y oblicuamente truncados en el ápice. Drupa muy carnosa, roja, tricoca, subgloboso trígona (a veces tetrágona) o trilobada, con tres surcos bien marcados, los ángulos romos, obtusa en ápice y base, de $1.2-2.5 \mathrm{~cm}$. de largo por 1.7-3 cm. de ancho, con estilos persistentes; pirenas trígonas con unas 5 crestas longitudinales dorsales provistas de prolongaciones carnoso fibrosas, la parte ventral con dos costillas paralelas muy próximas entre sí; semilla ovoidea.

Tipo en el Herbario Inst. Biol. Méx.: Yucatán, unos $2 \mathrm{~km}$. al S.E. de las Ruinas de Kabah, 9 ago. 1956, (O. G. Enríquez, 726).

Otros ejemplares: Yucatán, alrededores de Uxmal, 5 nov. 1955 (O. G. Enríquez, 265).

El nombre maya del arbusto descrito arriba es "oshté". La especie parece haber sido frecuentemente confundida con Malpighia punicifolia L. (véase, por ejemplo, Miranda in Massieu y otros; Ciencia, 15: 207. 1955); uno de los nombres citados por Standley según Gaumer (Flora of Yucatan; Field Mus. Bot. Ser. 3: 316. 1930) es "uzté". La diferencia de este vocablo con el citado más arriba puede derivar de la dificultad de representación de los sonidos mayas con el alfabeto castellano. La sh de "oshté" corresponde al sonido de esa grafía en inglés, sonido que no tiene correspondencia en castellano. A veces se representa ese sonido con la x ("oxté"), pero esto puede originar confusión con el sonido castellano correspondiente a la $\mathrm{x}$, confusión que se encuentra todavía aumentada en México donde la letra $x$ lleva a veces el sonido de $j$. Las variantes de o y u en la representación española de una misma palabra indígena derivan de la dificultad de representar ciertos sonidos de la o de los idiomas indígenas.

El nombre más frecuentemente usado actualmente en Yucatán para lo que parece ser Malpighia punicifolia es "guayacté". Massieu, Ruiz Quiles y Cravioto (Ciencia, 15: 207. 1955), fundándose en las diferencias entre el fruto del "oshté" y el de la "cereza de las Antillas", consideraron "probable que la variedad yucateca sea diferente de las puertoriqueñas". La exactitud de este punto de vista queda plenamente confirmada por el presente trabajo.

Malpighia souzae por sus estilos desiguales, sus dos estambres opuestos a los pétalos póstero laterales más robustos y el cáliz con 6 glándulas 
se agrupa con $M$. biflora Poir., $M$. lundellii Mort. y $M$. urens L. De estas especies la más cercana a $M$. souzae es $M$. incana, pero la segunda tiene hojas permanentemente canescentes debajo, agudas en la base y frutos relativamente pequeños. La localidad típica de $M$. incana, de donde procedieron las semillas cuyos ejemplares cultivados sirvieron para describir esa especie, fué dada como Campeche. No obstante $M$. incana no ha sido encontrada posteriormente en la Península de Yucatán. Niedenzu (Pflanzenreich IV. 141. 1928) cita esta especie únicamente de Cuba. Morton (Carnegie Inst. Wash. Publ. 461: 138. 1936), aunque sin duda, la incluye en la flora de la Península. Malpighia lundellii, descrita por este último autor (1. c.) de Belice, se distingue de $M$. souzae por sus hojas densamente seríceo argentadas debajo, redondeadas o retusas en el ápice, por sus largos (12-23 mm.) pedúnculos y por sus estilos uncinados.

Los frutos del "oshté" son comestibles y han sido el objeto de diversos estudios en el Instituto Nacional de Nutriología por R. O. Cravioto (Ciencia, 11: 13. 1951) así como por G. Massieu, A. Ruiz Quiles y R. O. Cravioto (Ciencia, 15: 206-207. 1955) que han hecho resaltar su alto contenido en vitamina C (más de $2 \mathrm{gr}$. \% en material fresco), comparable por tanto al de la "acerola" o "cereza de las Antillas" (Malpighia punicifolia).

La especie descrita en este trabajo ha sido dedicada a la memoria del distinguido botánico yucateco Narciso Souza Novelo, bien conocido por sus trabajos acerca de la flora de Yucatán y de la mitología maya. El fué el que envió las muestras de frutos del "oshté" que sirvieron en el Instituto Nacional de Nutriología para hacer los primeros análisis químicos de esa fruta.

Beltrania gen. nov. Euphorbiacearum (fig. 2)

Frutex erectus, pilis haud urentibus, simplicibus, ramulis interdum apice spinescentibus, foliis alternis saepe fasciculatis, margine sursum crenatis usque eubcrenatis, penninerviis. Flores dioici, in ramulis valde abbreviatis fasciculati. Fl. masculi in alabastro globosi; sepala 3-4 (saepius 3), valvata; discus nullus; stamina ad 30, pluriserialia, receptaculo convexo-columnari apice haud excavato inserta, filamentis brevibus, liberis, antheris erectis, oblongis, extrorsis, bilocularibus, ad basim affixis, connectivo angusto apice breviter triangulari apiculato; ovarii rudimentum nullum. Fl. feminei (in fructu tantum visi): sepala 5; discus nullus. Capsula bicocca, in coccos 2-valves dissiliens. Semina 2 subglobosa, testa crustacea, caruncula conspicua, membranacea, scutelliformi, testa adnata; embryo rectus; cotyledones planae, latae, subcordatae. 


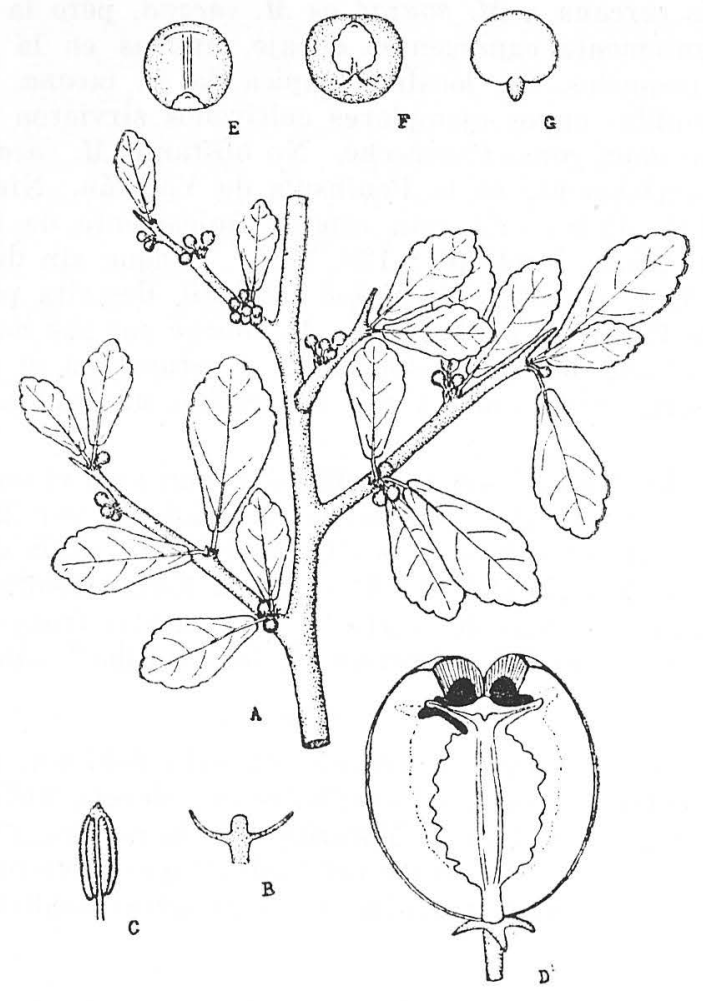

Fig. 2.-Beltrania crenatifolia. A, rama con hojas y flores masculinas en botón; B, corte longitudinal de flor masculina mostrando el receptáculo del cual se han quitado los estambres; C, estambre visto por fuera; D, fruto dehiscente mostrando uno de los cocos bivalvos y la columnilla central persistente; E, semilla vista por el lado ventral mostrando parte de la carúncula, el rafe y la ceja; F, semilla vista por arriba mostrando e] pico micropilar, la carúncula, el hilo y parte del rafe; G, embrión.

Especie tipo:

Beltrania crenatifolia sp. nov.

Frutex 1-2 m. altus. Folia membranacea vel chartacea, petiolis brevibus, 2-4 mm. longis, minute puberulis; lamina obovata vel rhomboideoobovata, $1.5-4.5 \mathrm{~cm}$. longa, 1-2.5 cm. lata, apice obtusa vel rotundata, basi abrupte longeque cuneata et rotundato-truncata vel subemarginata, margi- 
ne sursum crenata vel subcrenata, ceterum integra, nervis lateralibus utroque latere 3-4, supra glabra, subtus praeter axillas nerviorum lateralium fere glabra, inconspicue pellucido-puncticulata. Flores masculi breviter (1-3 mm.) pediceilati, in alabastro 2-3 $\mathrm{mm}$. lati; sepala ovata vel ovato-deltoidea. Flores feminei breviter (in fructu ad $4 \mathrm{~mm}$.) pedicellati; sepala lanceolata, $1.5 \mathrm{~mm}$. longa, extus dense pubescentia. Capsula subglobosa, 4-5 $\mathrm{mm}$. lata, caruncula albida ad $3 \mathrm{~mm}$. longa et $2.5 \mathrm{~mm}$. lata.

Arbusto erecto de 1 a $2 \mathrm{~m}$. alto, de pelos nunca urticantes, sencillos; corteza de las ramas gruesas gris y blanquecina, la de las jóvenes algo rojiza, éstas puberulentas y ligeramente flexuosas; ramillas a veces espinosas en el ápice. Hojas alternas, frecuentemente fasciculadas sobre brotes muy cortos o casi nulos; estípulas persistentes, triangular alesnadas, de 1-2 $\mathrm{mm}$. de largo, puberulentas cuando jóvenes; pecíolos delgados, de 2-4 $\mathrm{mm}$. de largo, menudamente puberulentos; lámina membranosa a cartácea, obovada a rómbico obovada, de 1.5-4.5 x 1-2.5 cm., obtusa a redondeada en el ápice, hacia la base bruscamente atenuado cuneada y redondeado truncada o emarginada en la base misma, crenada a subcrenada en el borde de la mitad superior, el resto del borde entero, penninervia, nervios principales poco marcados en el haz, algo prominentes en el envés, nervios laterales 3-4 pares, anastomosados a cierta distancia del borde, glabra arriba, glabra abajo salvo los mechones de pelos protectores de oquedades en las axilas de los nervios laterales, en el envés con diversas pequeñas glándulas más o menos alineadas de la base al ápice a los lados de la costilla, obscuramente pelúcido punticulada. Flores dioicas, fasciculadas en ramillas muy cortas bracteosas y foliáceas. Fl. masculinas cortamente (1-3 mm.) pediceladas, capullos florales globosos, de $2-3 \mathrm{~mm}$. de diámetro, puberulentos o pubescentes hacia el ápice; sépalos 3-4 (casi siempre 3), valvados, aovados o aovado-deltoideos; disco ninguno; estambres alrededor de 30 , en varias series, insertos en un pequeño receptáculo convexo columnar no ahuecado en el ápice, filamentos libres, cortos, anteras, erectas, oblongas, extrorsas, biloculares, basifijas, de 1.3-1.5 × 0.7 $\mathrm{mm}$., con tecas linear oblongas y conectivo angosto cortamente triangular apiculado en el ápice; rudimento del ovario nulo. Fl. femeninas (solamente vistas en fruto) cortamente (unos $4 \mathrm{~mm}$.) pediceladas, de pedirelos pubescentes; sépalos 5 , lanceolados, de unos $1.5 \mathrm{~mm}$. de largo, exteriormente densamente blanquecino pubescentes con pelos aplicados; disco nulo. Cápsula bicoca, subglobosa, de 8-9 × $7 \mathrm{~mm}$., glabra, con 4 ligeras costillas longitudinales, dehiscente en cocos bivalvos que se separan de una persistente columnilla central bialada. Semillas 2 subglobosas, con la cara correspondiente al rafe aplanada, de 4-5 mm. de diámetro, de testa crustácea, pardusca con manchas blancas irregulares, menudamente rugoso tuberculada, glabra, con carúncula conspicua, membranosa, en forma de escudete, adherida a la testa, blanquecina, de unos $3 \times 2.5 \mathrm{~mm}$., la testa tiene un pequeño pico en la zona del micropilo y una arruga a modo 
de ceja de unos $3.5 \mathrm{~mm}$. de largo en la terminación del rafe; endospermo carnoso; embrión recto, con cotiledones planos, anchos, subcordados.

Tiipo en el Herb. Inst. Biol. Méx.: Yucatán, medio kilómetro al suroeste de Chicxulub (al este de Progreso), en matorral bajo algo secundario sobre el cordón litoral cerca del borde de la "ciénaga", 15 sept. 1954 (Miranda, 8057; fl. masc.).

Otros ejemplares: Yucatán, en el cordón litoral entre El Cuyo y Los Colorados, 6 oct. 1955 (O. G. Enríquez, 148; fr.).

Las afinidades del género Beltrania, a causa de la falta de conocimiento de sus flores femeninas y en especial de los estilos, permanecen algo inciertas. Evidentemente Beltrania se incluye en la Tribu Acalypheae Muell. Arg. según la común delimitación de ésta (ver Pax et K. Hoffm. in Engler Pflanzenfamilien, 2 Aufl., band 19c: 35. 1931), pero la falta de observaciones referentes a la disposición de los estilos hace inseguro determinar si ese género deba ser adscrito a la Subtribu Mercurialinae Pax o a la Plukenetiinae Pax.

El aspecto general de la planta aquí descrita, con sus ramas espinosas, sus mechones de pelos axilares en el envés de las hojas, éstas pelúcido punticuladas y sus flores fasciculadas en ramas muy cortas, recuerda mucho al género Adelia L. y particularmente a $A$. barbinervis Schlecht. et Cham. Es posible que los ejemplares considerados por Standley en su "Flora of Yucatan" (Field Mus., Bot. Ser. 3: 319. 1930) con duda como esta última especie pertenezcan en realidad a Beltrania. No obstante lo indicado, la falta de disco floral, los estambres más numerosos y las semillas carunculadas hacen difícil incluir a este último género en la Serie Adeliiformes Pax et Hoffm. (Subtribu Mercurialineae) cerca de Adelia. Por otro lado, Beltrania muestra también ciertas concordancias con el género Acidoton Sw. (Subtribu Plukenetiinae) de las Antillas, pero la falta en el primero de pelos urticantes, sus hojas crenadas, flores estrictamente fasciculadas, ovario bilocular y presencia de carúncula en la semilla son caracteres que no parecen indicar estrecho parentesco entre esos dos géneros.

Me ha sido grato nombrar este género en homenaje al destacado biólogo mexicano Prof. Enrique Beltrán, Director del Instituto Mexicano de Recursos Naturales Renovables, institución que patrocinó los estudios de la Península de Yucatán, durante el transcurso de los cuales fueron recolectados los ejemplares tipos de esta notable planta. 